\title{
Um Sistema Colaborativo de Apoio à Construção de Roteiros de Viagem
}

\author{
Daniel Ramos, Fellipe Ferrão, Rosa Maria Costa, Maria Clicia S. de Castro \\ Departamento de Informática e Ciência da Computação \\ Universidade do Estado do Rio de Janeiro (URJ) \\ Rua São Francisco Xavier, 524 - 20.559-900 - Rio de Janeiro - RJ - Brazil \\ rosamcosta@yahoo.com, cliciadime.uerj.br
}

\begin{abstract}
This paper presents a system that integrates GPS technology with a mashup that combines Google Maps with an application developed for mobile devices. This application enables the collaborative creation of travel itineraries, providing information related to places chosen by users. The Mashup informs the user's location in real time and displays information about their surroundings.
\end{abstract}

Resumo. Este artigo apresenta um sistema que integra a tecnologia GPS com um mashup que combina o Google Maps com uma aplicação desenvolvida para equipamentos móveis. Este aplicativo possibilita a criação colaborativa de roteiros de viagem, disponibilizando informações relacionadas aos lugares escolhidos pelos usuários. O Mashup informa a localização do usuário em tempo real e mostra informações referentes ao seu entorno.

\section{Introdução}

A tecnologia móvel tem recebido uma atenção especial de pesquisadores e desenvolvedores. Em particular, a crescente difusão e popularidade de telefones celulares, amplia as possibilidades de comunicação, de entretenimento e de acesso a informações. A criação de aplicativos para celulares é uma área bastante promissora, pois contempla um grande número de usuários e cria mercados com perspectivas de altos lucros comerciais. Neste caso, os aplicativos se tornam mais elaborados, com tendências de compartilhamento e de fácil acesso às informações, caracterizados pelos novos direcionamentos estratégicos da Internet.

Neste contexto, a Web 2.0 se destaca por explorar um modelo interativo, que valoriza a inteligência coletiva, a participação colaborativa e a propagação rápida de conhecimento entre os usuários que interagem através da web. Ela tem sido considerada como a segunda geração de comunidades e serviços, que visa incentivar a criatividade e o compartilhamento [O'Reilly, 2005].

Visando integrar as possibilidades da Web 2.0 aos serviços móveis, este artigo apresenta um sistema que integra a tecnologia GPS (Global Position System) ao serviço de utilização de mapas do Google, para gerar um mashup que apóia usuários na definição e acompanhamento de roteiros de viagem. Esse sistema é denominado Próxima Parada. Ele informa a localização do usuário em tempo real e disponibiliza informações relacionadas ao entorno do local onde o usuário se encontra. Dessa forma, o usuário pode determinar pontos de parada, programando o roteiro de sua viagem. 
Este artigo está organizado da seguinte forma: na Seção 2 descrevemos brevemente os conceitos e as tecnologias utilizados no sistema Próxima Parada. Na Seção 3 apresentamos uma visão geral do sistema. Na Seção 4 mostramos a especificação e o sistema desenvolvido. Finalizamos, apresentando alguns comentários.

\section{Conceitos e Tecnologias}

A tecnologia móvel tem exigido cada vez mais a utilização de diferentes ferramentas e tecnologias desenvolvidas especialmente para ela, devido as suas particularidades. Os celulares, na última década, se tornaram o meio de comunicação mais bem sucedido do mundo. Só no Brasil, são cerca de 175 milhões de acessos móveis (Anatel, 2010), e esse crescimento não tem sido muito diferente em outros países. Em nível mundial o celular tem aproximadamente 3 bilhões de usuários. As empresas têm percebido a necessidade de investir na padronização de aplicações e componentes, de modo a melhor aproveitar o potencial desses dispositivos.

A Web 2.0 [O'Reilly, 2005] pode ser entendida como um conjunto de princípios e práticas voltados para a Internet, tendo como características: ser uma plataforma de serviços, explorar uma arquitetura que enfatize a participação, ter potencial de escalabilidade, mesclar fontes de dados e de transformação de dados, disponibilizar software utilizável em vários tipos de dispositivos e aplicações que atuam como potencializadores da inteligência coletiva. A Web 2.0 baseia-se em um modelo interativo que valoriza a participação colaborativa e a propagação de conhecimento rápida entre os usuários que interagem através de web sites.

É neste contexto em que os mashups [Merril, 2006] se inserem. Eles podem ser considerados um tipo de aplicação da Web 2.0, uma vez que seguem os seus princípios. Mashups são serviços criados pela combinação de diferentes aplicativos para a Internet.

As aplicações de software que rodam em dispositivos móveis só se expandiram a partir da criação de sistemas operacionais específicos. O Android desenvolvido inicialmente pela Google e posteriormente, pelo grupo The Open Handset Alliance [Open Handset Alliance, 2007] é um sistema operacional móvel, sendo considerado como uma plataforma multitarefa, sendo adotado por várias empresas de telefonia celular. O Android é um ambiente que segue um padrão no qual desenvolvedores e criadores de hardware podem se adequar para gerar produtos que sejam compatíveis entre si. $\mathrm{O}$ desenvolvimento do Android foi baseado no Kernel 2.6 Linux. Ele é responsável pelo gerenciamento de memória, threads, redes e drivers, além de segurança. Esse gerenciamento permite o paralelismo das aplicações. Ele executa tanto os serviços em segundo plano, não visíveis pelos usuários, quanto os aplicativos acessados e utilizados pelos usuários. No desenvolvimento de aplicações, é utilizada a linguagem Java [Oracle, 2007], permitindo usufruir praticamente de todos os recursos que essa plataforma oferece.

Por outro lado, o sistema de posicionamento GPS (Global Position System) [Dana, 1997] utiliza satélites artificiais para definir uma localização geográfica baseado em dados de altitude, latitude e longitude. A partir das coordenadas de pelo menos 4 satélites, utilizando o mesmo sistema de referência entre eles e a antena do receptor, é possível calcular, a partir de suas distâncias, em que posição (latitude, longitude e 
altitude) o receptor se encontra. O princípio de funcionamento do GPS é a recepção de sinais por um receptor, que pode estar presente em um aparelho celular, por exemplo.

Vários serviços baseados em localização (Location Based Service - LBS) são disponibilizados para telefonia móvel. O Yelp [Yelp, 2011] para celulares com sistema operacional Android oferece um guia de cidades (online) que auxilia pessoas a encontrar lugares para comer, comprar, beber e lazer. As informações são baseadas em opiniões informadas por uma comunidade. Sua funcionalidade é similar a proposta deste trabalho, pois é um software livre, mas difere porque não utiliza a tecnologia GPS.

Em [Kuhnen, 2003] é descrito um protótipo de uma aplicação LBS que identifica um estabelecimento a partir de uma localização informada, também usa a tecnologia GPS, mas não disponibiliza informações sobre os estabelecimentos que indica.

Estes conceitos são a base para o desenvolvimento de um aplicativo para celulares, que é descrito a seguir.

\section{O Sistema Próxima Parada}

Atualmente, uma parcela cada vez maior da sociedade recorre a Internet para obter mais conhecimento e informação, aumentando a demanda de sistemas eficazes e inteligentes, capazes de reunir em uma navegação rápida todo o conteúdo que necessitam. É com esse objetivo que o sistema proposto está estruturado. Ele possibilita que o usuário do sistema possa compartilhar informações com outros usuários. A idéia é compartilhar experiências de viagens, implementando o conceito de computação colaborativa. Todo o conteúdo do sistema é construído através da interação entre seus usuários, evoluindo e expandindo o sistema a cada vez que for difundido e utilizado.

A Figura 1 apresenta uma visão geral do sistema Próxima Parada.

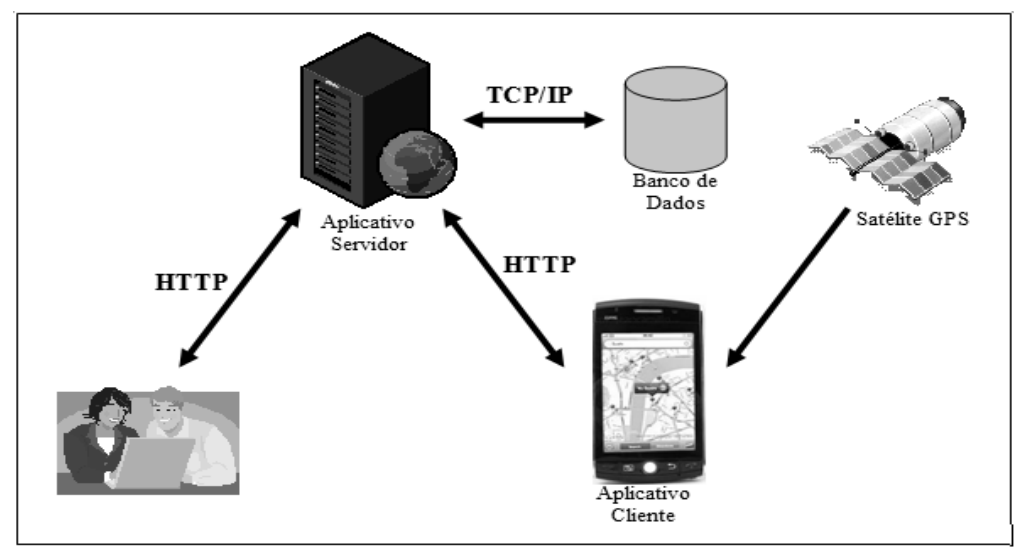

Figura 1. Visão geral do sistema Próxima Parada

Como pode ser observado na Figura 1, o sistema Próxima Parada possui basicamente dois módulos: Servidor e Cliente, que estão descritos a seguir. 


\subsection{Módulo Servidor (mashup site)}

O módulo Servidor possibilita que os usuários cadastrem informações sobre suas viagens, destacando seus destinos e pontos de interesse. Para isso, o Servidor utiliza os mapas disponibilizados pelo mashup site do Google [Silva, 2009]. Após selecionar um destino, o usuário pode optar por cadastrar no mapa locais que julgou interessantes, ou selecionar pontos já cadastrados por outros usuários e inserir informações complementares. Tais pontos de interesse são cadastrados de acordo com o seu tipo, sendo identificados por uma imagem específica. Por exemplo, restaurantes, postos de gasolina, pontos turísticos, hotéis, entre outros.

Para cada ponto selecionado o usuário pode adicionar comentários, fornecendo críticas ou comentários, para que outros usuários possam obter essas informações a respeito desses locais.

\subsection{Módulo Cliente}

O módulo Cliente disponibiliza uma consulta rápida a pontos selecionados através do celular. Atualmente os celulares integram diversas funcionalidades, acesso a Internet e navegação através de GPS. Aproveitando essas facilidades, o módulo Cliente as combina para disponibilizar aos seus usuários consultas para definir roteiros de viagem e acesso às informações sobres os pontos escolhidos.

Através do GPS, o sistema identifica a posição do usuário, levanta todos os pontos adjacentes aos locais onde o usuário se encontra, ou planeja ir, os desenha na tela do celular, possibilitando a consulta de seu conteúdo.

O Cliente consome as informações através de um Webservice que faz parte do sistema Servidor (mashup site), permitindo que as informações estejam sempre sincronizadas com o que está ocorrendo na Web.

\section{Especificação e Implementação do Sistema Próxima Parada}

Esta seção descreve a documentação base para o desenvolvimento do sistema, demonstrando o seu fluxo de funcionamento e o mapeamento das suas funcionalidades. A seguir, são descritos os requisitos do sistema Próxima Parada, as especificações dos casos de uso e a sua implementação.

\subsection{Requisitos Funcionais}

O sistema atende aos seguintes requisitos funcionais: i) permitir que um usuário da Internet se cadastre no sistema e utilize seus serviços; ii) possibilitar ao usuário a manutenção de dados pessoais, bem como os dados de seus mapas, no sistema servidor; iii) permitir ao usuário tornar seus pontos públicos ou mantê-los privados; iv) localizar os mapas relativos às viagens ou aos pontos de interesse e exibir ou não, os pontos definidos como públicos; v) possibilitar ao usuário o acesso aos pontos cadastrados, através do sistema cliente do celular; e vi) permitir que determinados tipos de usuários atuem como administradores, removendo usuários e excluindo comentários indesejáveis. 


\subsection{Requisitos Não Funcionais}

Os seguintes requisitos não funcionais estão presentes no sistema: segurança, desempenho e usabilidade, que estão descritos a seguir.

- Segurança. Os módulos devem garantir a confiabilidade e segurança das informações cadastradas pelos usuários, caso estes não desejem tornar seus dados públicos (dados pessoais e rotas de viagem).

- Desempenho. Considera o tempo de resposta. Neste caso, o módulo Cliente deve ter uma rápida atualização da localização através do GPS, para aumentar a confiabilidade do usuário.

- Usabilidade. A usabilidade está relacionada à interface gráfica, ela deve ser amigável, simples e acessível. O módulo Cliente, por estar disponível em aparelhos portáteis, deve possuir uma interface especialmente preparada para utilização em pequenas telas. É importante a utilização de fontes não muito pequenas e cores que sejam facilmente diferenciáveis uma das outras. Além de estar preparada para utilização em ambientes externos, de modo que diferentes luminosidades ou ruídos externos não influenciem a visualização das informações. O módulo Servidor deve possuir uma interface clara e intuitiva, de modo a permitir ao usuário utilizar o sistema sem necessitar de nenhum tipo de treinamento.

\subsection{Diagramas de Caso de Uso}

\subsubsection{Atores}

Para este modelo de casos de uso foram identificados três tipos de atores em nosso sistema: o Usuário, o Administrador e o Robô, que estão descritos a seguir.

Usuário. Localizado em ambos os sistemas Cliente e Servidor, o usuário do sistema é responsável pelo cadastro e consulta das informações relativas aos percursos das viagens. Ele pode estar em algum terminal conectado à Internet realizando tarefas como cadastro, consulta e manutenção das informações inseridas, ou pode estar em qualquer outro local, em que seja possível utilizar de seu celular com GPS e acesso à Internet, para acesso às informações do sistema. $\mathrm{O}$ sistema deve estar preparado para um grande número de usuários, da ordem de milhões, acessando o sistema simultaneamente, já que sua utilização por este ator se pode se tornar freqüente.

Administrador. Localizado no sistema Servidor, o administrador do sistema é responsável pela manutenção e moderação do sistema. Ele pode ser visto como um tipo avançado de usuário, pois tem o poder de excluir comentários e marcações de usuários e até mesmo para bloqueá-los. O número de administradores é pequeno, podendo ser menor do que $0,5 \%$ do total de usuários, além de sua utilização ser ocasional.

Robô. Localizado no sistema Cliente, o robô é o ator responsável pela atualização da localização dos atores nos mapas do sistema. Através da conexão com o GPS, ele informa ao sistema a coordenada física sobre o mapa onde se encontra o usuário no momento em que este estiver acessando o sistema através do celular. Sua interação com o sistema é constante. O número de robôs ativos é proporcional à quantidade de usuários conectados ao sistema através do celular. 


\subsubsection{Caso de Uso}

A Figura 2 mostra o diagrama de caso de uso dos módulos Cliente e Servidor, com o intuito de descrever todas as ações do sistema atribuídas aos seus respectivos atores.

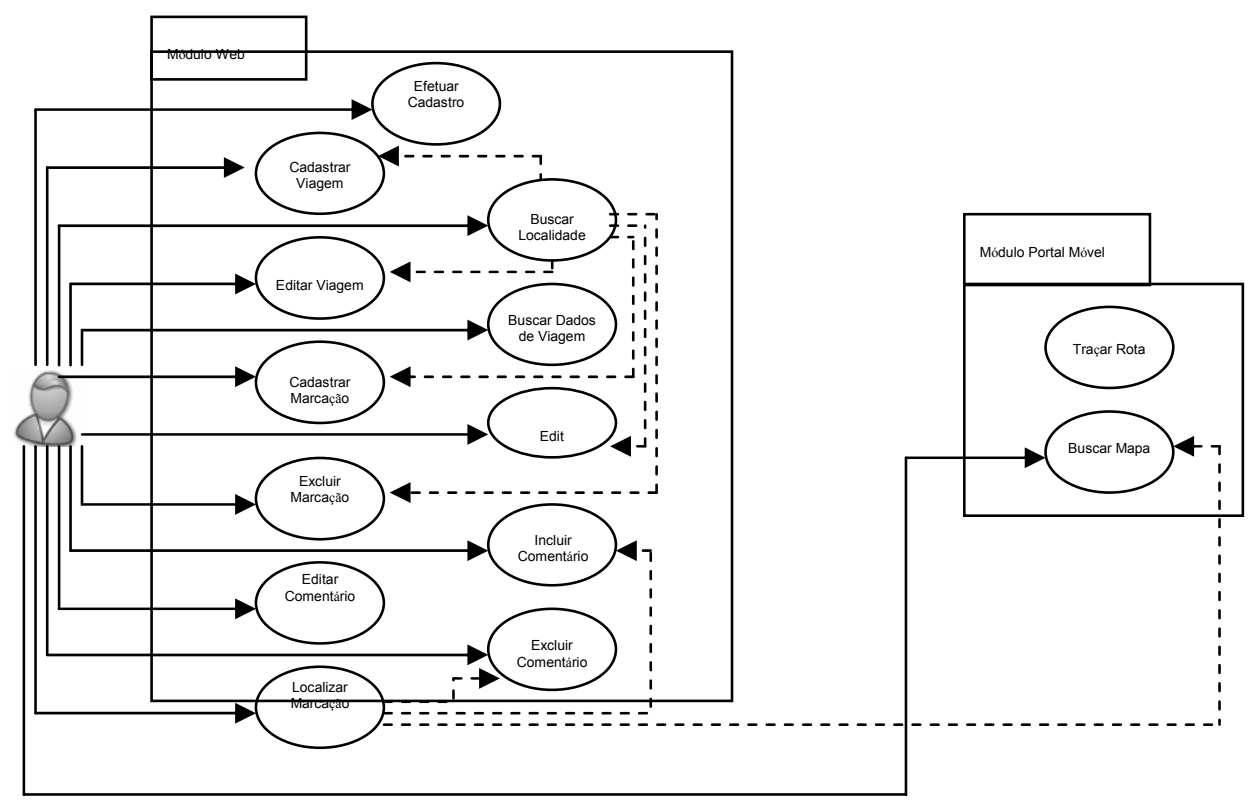

Figura 2. Diagrama de caso de uso do ator usuário

Como podemos observar, o ator usuário possui uma função essencial tanto no módulo Cliente, quanto no módulo Servidor, fornecendo todo o conteúdo necessário para que a integração dos serviços ocorra.

A Figura 3 mostra os diagramas dos atores robô e administrador, que dão suporte a todas as operações realizadas pelo usuário.

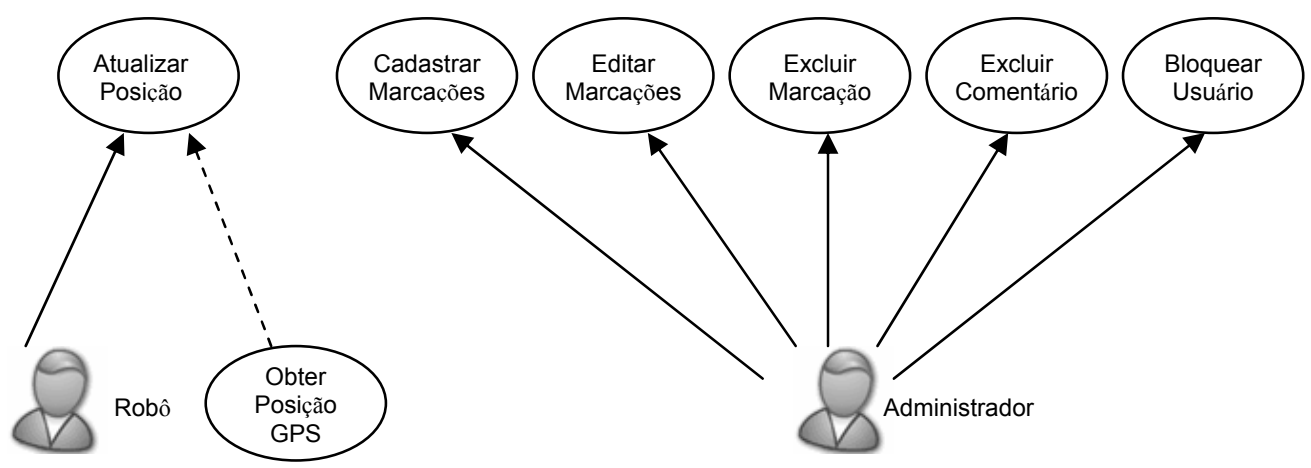

Figura 3. Diagrama de caso de uso dos atores administrador e robô

\subsection{Implementação do Sistema}

A implementação proposta utiliza dois diferentes aplicativos. O primeiro é um aplicativo Servidor online, responsável pelo cadastro e manutenção das marcações e informações referentes às rotas de viagem do usuário. Ele pode ser acessado através de 
qualquer computador que possua uma conexão à Internet. $\mathrm{O}$ segundo aplicativo é um Cliente do aplicativo Servidor. Ele deve ser acessado pela Internet através do celular com GPS e exibe ao usuário as informações cadastradas no aplicativo Servidor, atualizadas de acordo com sua posição geográfica indicada pelo GPS, ou por sua interação direta.

Para utilizar o sistema Próxima Parada é necessário realizar o acesso ao sistema através de um login e uma senha. O usuário pode, então, buscar o mapa de uma determinada região, percorrer o mapa e marcar os pontos que acha interessante conhecer ou ter como referência, traçando assim um roteiro de viagem.

Nos pontos cadastrados o usuário pode, ao se encontrar em um local, utilizar seu celular com GPS para sua localização física em relação às marcações e pontos já cadastrados no sistema Servidor. Na medida em que ele se desloca em relação ao mapa, essas informações são atualizadas. É possível também, para uma determinada marcação no mapa, visualizar os comentários de outras pessoas em relação àquele ponto.

Os aplicativos foram desenvolvidos segundo o modelo de arquitetura MVC (Model View Controller) [Burbeck, 1992] em Java (Oracle, 2007) (versão jre_1.6.0_13), através da IDE Eclipse [Genuitec, 2003] por se tratar de uma linguagem gratuita bastante conhecida e com número crescente de usuários. Também são utilizados o Tomcat [The Apache Software Foundation, 1999] como Servidor Web (versão 6.0.20) e a framework Hibernate para a persistência de dados.

\subsection{Classes}

A seguir são citadas as principais classes referentes ao projeto do sistema Próxima Parada. É importante ressaltar que existem outras classes que também fazem parte do sistema, mas que não são apresentadas e que estão relacionadas ao suporte do ambiente.

FacesServlet. Classe interna ao framework JSF, responsável por coordenar todas as requisições feitas no browser de Internet, interpretando-as e selecionando a classe interna ao sistema responsável por tratar a requisição.

Usuário. Classe responsável por manipular e persistir no banco de dados, todas as atividades relacionadas ao usuário do sistema, dando suporte ao cadastro, controle de acesso e por manter o histórico de atividades no sistema.

Viagem. Classe responsável por manipular e persistir no banco de dados, todas as atividades relacionadas a viagens. Ela possui uma série de validadores para que o usuário possa obter através de fragmentos de endereço, uma localização geográfica precisa do local que está sendo pesquisado. Para isso, essa classe utiliza métodos de acesso sofisticados ao mashup site do Google Maps [Silva, 2009]. Essa classe também provê as posições geográficas necessárias para os posicionamentos dos pontos no mapa.

Ponto. Classe responsável por manipular e persistir no banco de dados, todos os pontos de interesse de uma determinada viagem. Ela possui métodos de integração com todas as outras classes do sistema, compondo uma série de validadores para eles.

Comentario. Classe responsável por manipular e persistir no banco de dados todos os comentários relacionados aos pontos de interesse de uma determinada viagem. 


\subsection{Descrição de Atividade e Diagramas de Sequência}

\subsubsection{Aplicativo Servidor}

O aplicativo Servidor é disponibilizado como um portal de acesso na Internet e pode ser acessado por qualquer usuário cadastrado. Outra característica desse aplicativo é o suporte a Webservice, tornando possível a comunicação entre o Servidor e os aplicativos Clientes de maneira fácil, rápida e segura.

Nesse aplicativo além do cadastro das informações sobre as rotas de viagem, é utilizado o serviço oferecido pela Google Inc. para utilização de mapas (mashup), os quais, ao serem visualizados pelos usuários, fornecem a interface gráfica para a inclusão dos pontos do roteiro de viagem.

As marcações (pontos) e comentários inseridos no mapa, assim como as informações do usuário, ficam armazenados em um banco de dados. É importante ressaltar que somente as referências dos mapas utilizados, como posições geográficas, são armazenadas. Esses dados são utilizados para buscar a visualização dos mapas, serviço oferecido pelo Google. Não há armazenamento de imagens ou mapas pelo Servidor.

O fluxo de funcionamento principal do sistema Próxima Parada está exemplificado através a um cenário. Nesse cenário, o usuário cadastra determinadas localidades ou pontos (país, estado e cidade) de sua próxima viagem para que, posteriormente estando nessa cidade, ele possa se localizar em relação a elas.

Ao inserir corretamente suas informações para acesso ao sistema, é exibida a tela inicial. Caso o usuário tenha viagens anteriores cadastradas, ele visualiza um resumo de suas últimas viagens.

Uma vez cadastrada a viagem, o sistema utiliza os dados geográficos inseridos para carregar e exibir o mapa do local referenciado, onde o usuário pode cadastrar os pontos do mapa que farão parte do seu roteiro de viagem ou que poderão lhe servir de referência. Selecionando no mapa uma determinada localidade para ser ponto, a tela de Cadastro de Ponto é exibida para inclusão de informações e escolha da imagem relacionada àquele ponto, que é visualizada no mapa.

A Figura 4 ilustra a tela de visualização do mapa de viagem.

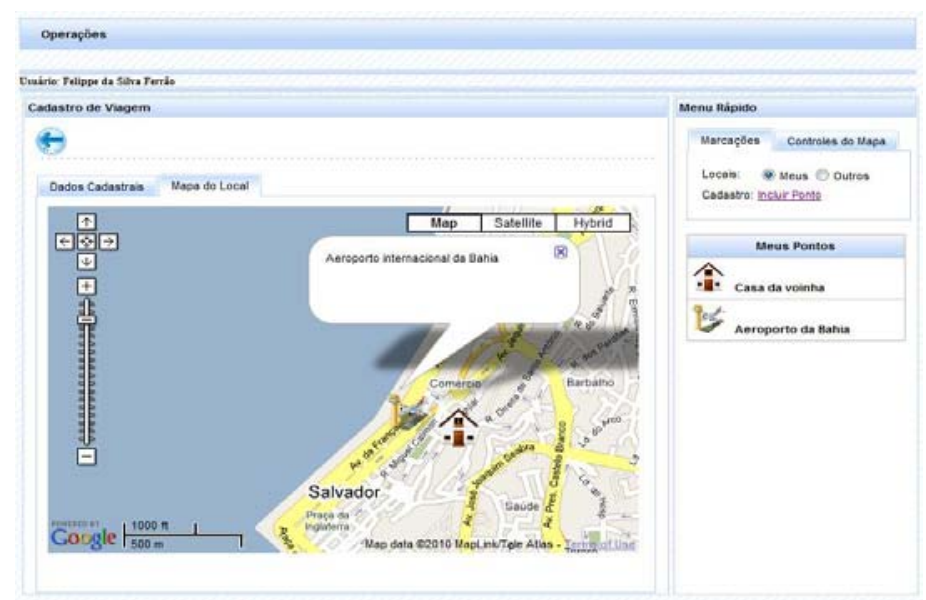

Figura 4. Tela de Visualização do Mapa da Viagem para a cidade de Salvador 
Para cada ponto, o usuário tem a opção de inserir um comentário sobre aquele ponto, para auxiliar a sua consulta. $\mathrm{O}$ usuário pode repetir o ciclo de cadastro de pontos e colocar todas as referências que formarão o seu roteiro, com os devidos comentários.

Uma vez que todos seus pontos tenham sido cadastrados, o fluxo de cadastro de sua viagem está terminado.

\subsubsection{Aplicativo Cliente}

O aplicativo Cliente foi desenvolvido utilizando a tecnologia Android, permitindo que ele seja simples e robusto, características ideais para aplicativos que necessitam ser executados em celulares e PDAs.

Através do acesso ao aplicativo Cliente pelo celular, o usuário é capaz de buscar todas as suas viagens e seus respectivos pontos cadastrados no sistema Servidor. O aplicativo Cliente se comunica com o aplicativo Servidor através de WebService, disponibilizando todo o conteúdo online de forma interativa.

Supondo que o usuário se encontra na cidade cadastrada e através de seu celular com GPS, acesse o sistema para visualizar sua rota de viagem. Ele terá a viagem para Salvador que foi cadastrada anteriormente disponível para visualização, como mostrado na Figura 5. O mapa com seus pontos é exibido e o usuário consegue então se localizar em relação às suas rotas e referências registradas.
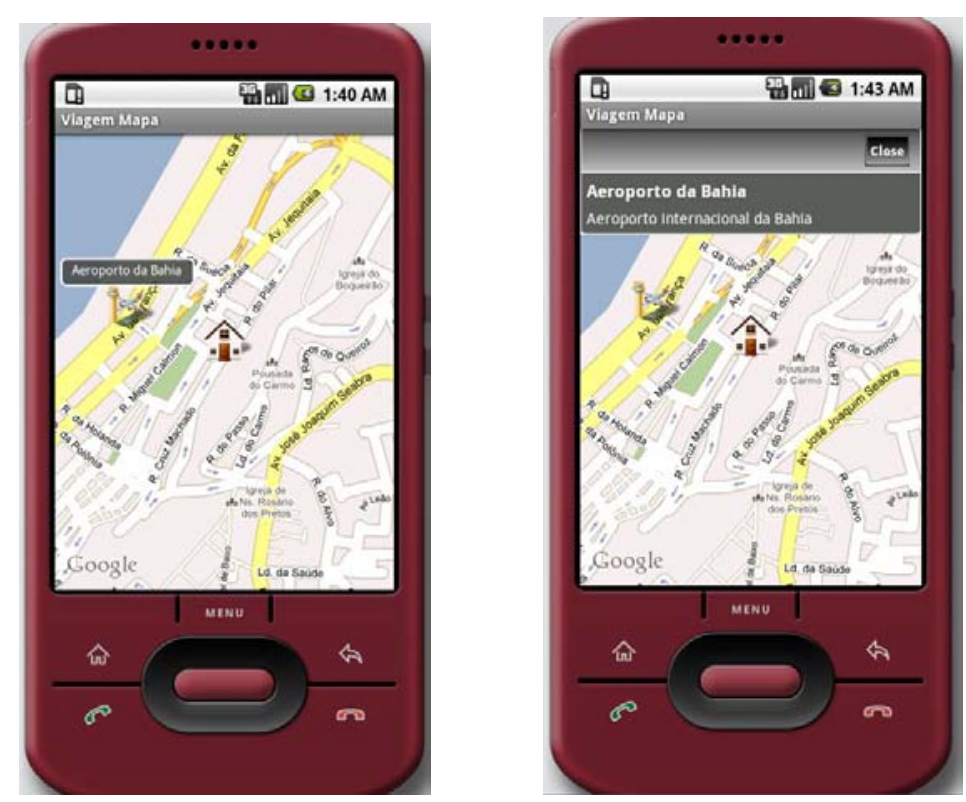

Figura 5. Tela de Seleção de Viagens, com os pontos cadastrados previamente, visualizados no aplicativo Cliente

Os diagramas de Sequência dos aplicativos Servidor e Cliente pode ser visto nas Figuras 6 e 7. 


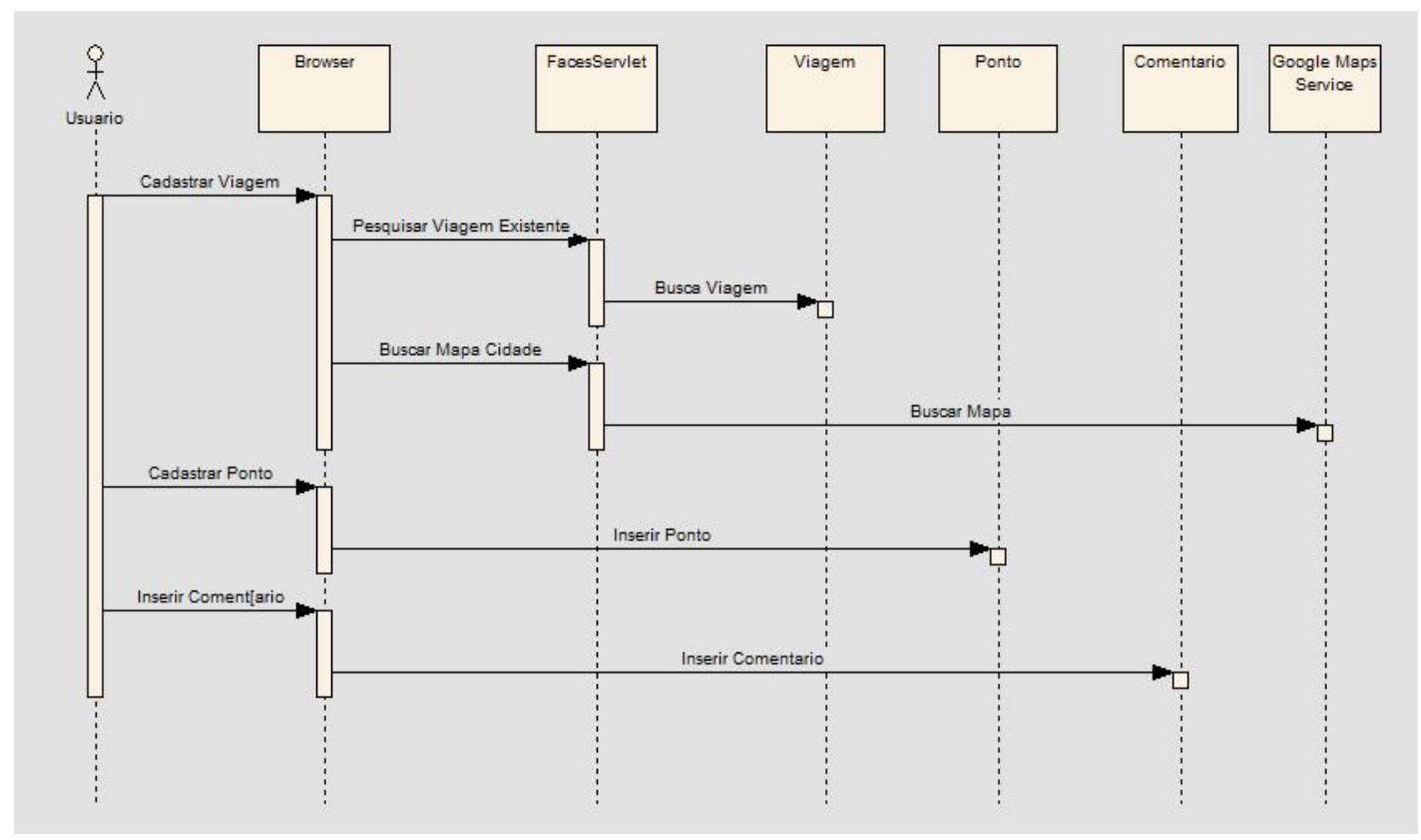

Figura 6. Diagrama de Seqüência do aplicativo Servidor

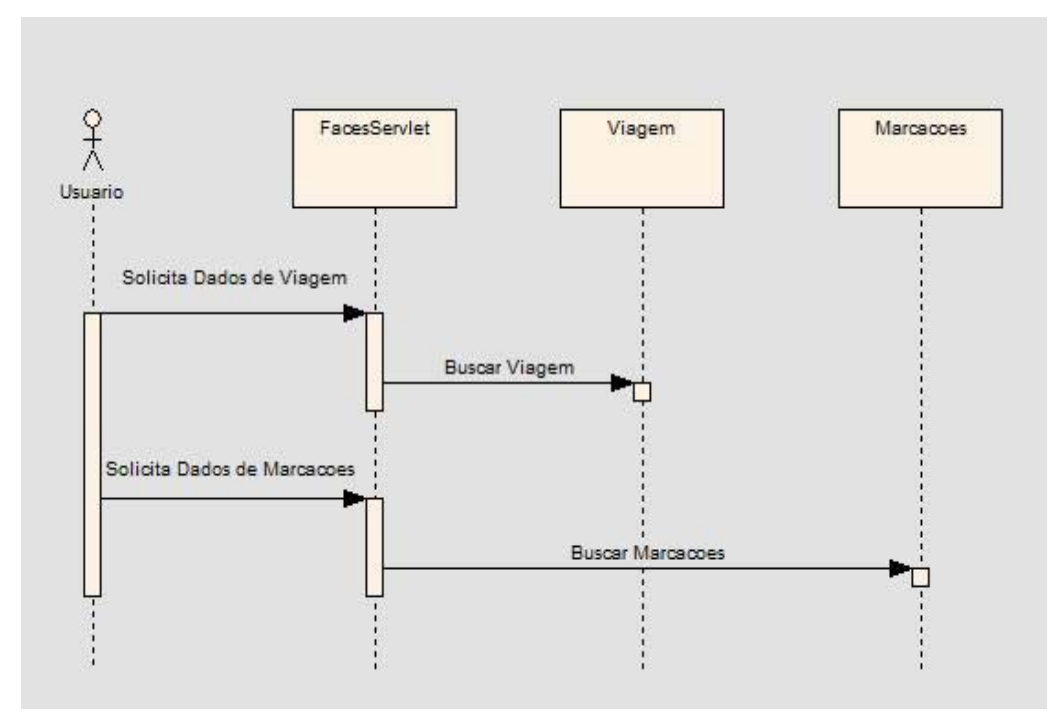

Figura 7. Diagrama de Seqüência do aplicativo Cliente

\section{Conclusões}

Este trabalho descreveu uma aplicação voltada para apoiar um usuário na construção e armazenamento de rotas de viagem, para posteriores consultas via celular. Por ser de fácil entendimento e utilização, não exigindo nenhum tipo de treinamento ou manual, esta aplicação poderia se difundir em diferentes contextos relacionados a viagens.

As maiores dificuldades encontradas no desenvolvimento do sistema relacionaram-se à integração das tecnologias utilizadas. No caso do Android, por ser uma tecnologia relativamente nova, ainda que haja documentação no site oficial do projeto, enfrentamos dificuldades para encontrar respostas para dúvidas sobre as limitações da plataforma. Alguns fóruns, wikis e grupos de discussão foram 
fundamentais para a superação dos problemas, reforçando a idéia de colaboração, que caracteriza a fase atual da Internet.

A idéia central do sistema é oferecer meios para que o usuário acesse informações sobre lugares que vai visitar. Porém, esse sistema pode ser expandido para outros propósitos, visto que é possível visualizar pontos e comentários de uma região, cadastrados por outros usuários, viajantes, habitantes, comerciantes e empresários daquela localidade. O Sistema poderia até mesmo ser disponibilizado como um serviço para outro Sistema que necessite de dados de referência em mapas.

\section{Referências}

Anatel. (2010) Brasil tem mais de 175 milhões de acessos móveis. Disponível em http://www.anatel.gov.br/Portal/exibirPortalNoticias.do?acao=carregaNoticia\&codig o=19695, Acesso em agosto de 2010.

Cornell, G. and Horstmann, C., (2000) Core Java 2: Fundamentos. Volume 1. Editora: Makron Books.

Dana, P., (1997) Global Positioning System Overview. Disponível em http://www.colorado.edu/geography/gcraft/notes/gps/ gps_f.html. Acesso em julho de 2009.

Kuhnen, Alex, (2003) Protótipo de uma aplicação LBS utilizando GPS conectado em celular para consultas de dados

Georeferenciados, (2003) Universidade Regional de Blumenau, Santa Catarina. Disponível http://campeche.inf.furb.br/tccs/2003 II/2003-2alexkuhnenap.pdf. Acesso em março de 2012.

Merril, D., (2006) Mashups: The New Breed of Web Applications. Disponível http://www.ibm.com/developerworks/xml/ library/x-mashups/index.html. Acesso em agosto de 2010.

Open Handset Alliance, (2007) Disponível em http://www.openhandsetalliance.com/index.html. Acesso em agosto de 2009.

Silva, L., (2009) Mashups com Google Maps API. Revista Java Magazine. Editora DevMedia. Edição 64.

O'Reilly, T., 2005. What Is Web 2.0. Disponível em http://oreilly.com/web2/archive/what-is-web-20.html. Acesso em janeiro de 2011.

The Apache Software Foundation, (1999) Disponível http://tomcat.apache.org/. Acesso em agosto de 2010 .

Genuitec, (2003) My Eclipse Infinite Possibilities. Disponível em http://www.myeclipseide.com/htmlpages-func-display-pid18.html?gclid=CPqM5ZD5xKkCFYfs7QodbVIlWw. Acesso em agosto de 2010.

Oracle, (2007) The Java EE 5 Tutorial. Disponível em http://download.oracle.com/javaee/5/tutorial/doc/bnadr.html. Acesso em agosto de 2010 . 
Burbeck, S., (1992) Applications Programming in Smalltalk-80(TM): How to use Model-View-Controller (MVC). Disponível http://st-www.cs.illinois.edu/users/ smarch/st-docs/mvc.html

Yelp, (2011) Disponível em http:// www.yelp.com. Acesso em março de 2012. 